\title{
Participatory Approach to Natural Hazard Education for Hydrological Risk Reduction
}

\author{
Giovanna Lucia Piangiamore and Gemma Musacchio
}

\begin{abstract}
Modern Society needs interactive public discussion to provide an effective way of focusing on hydrological hazards and their consequences. Embracing a holistic Earth system Science approach, we experiment since 2004 different stimulating educational/communicative model which emotionally involves the participants to raise awareness on the social dimension of the disaster hydrogeological risk reduction, pointing out that human behavior is the crucial factor in the degree of vulnerability and the likelihood of disasters taking place. The implementation of strategies for risk mitigation must include educational aspects, as well as economical and societal ones. Education is the bridge between knowledge and understanding and the key to raise risk perception. Children's involvement might trigger a chain reaction that reinforce and spread the culture of risk. No matter how heavy was the rain that hit our land in the past and recent seasons, we still are not prepared. If on one hand we need to fight against worsening Global Warming that trigger extreme meteorological events, we should also work on sustainable land use and promote landscape preservation. Since science can work on improving knowledge of phenomena, technology can provide modern tool to reduce the impact of disasters, children and adults education is the flywheel to provide the change. We present here two cases selected among the wide range of educational activities that we have tested and to which more than 2,000 students and adults have participated within a period of 12 years. They include learn-by-playing, hands-on, emotional-learning activities, open questions seminars, learning paths, curiosity-driven approaches, special venues and science outreach.
\end{abstract}

\section{Keywords}

Natural hazard • Hydrogeological risk $\bullet$ Prevention $\bullet$ Territory $\bullet$ Participatory approach $\bullet$ Awareness raising - Resilience

G.L. Piangiamore $(\bowtie)$

Istituto Nazionale di Geofisica e Vulcanologia,

Sez. Roma 2-Sede di Portovenere, via Pezzino Basso, 2,

19025 Fezzano di Portovenere (SP), Italy

e-mail: giovanna.piangiamore@ingv.it

G. Musacchio

Istituto Nazionale di Geofisica e Vulcanologia, Amministrazione Centrale, via di Vigna Murata 605, 00143 Rome, Italy

e-mail: gemma.musacchio@ingv.it

\section{Introduction}

The public understanding of science has a strong impact on the social debate upon natural hazards, environment, resources and sustainability. However although Eurobarometer 2011 data reveals that $75 \%$ of EU citizens are positive about science, since 2005 the share of Europeans experiencing trust in science has declined from 78 to $66 \%$. The 
largest decline in trust has taken place in Germany, Italy and Poland.

The improvement of science understanding has on one end supported citizens towards independent opinions and participation to crucial decisions; on the other end it seems to build skepticism towards the institutional settings where knowledge generation takes place. Due to the complexity, and yet the uncertainty, of the nowadays process of building up knowledge in science, new discoveries and claims can be contested, leave ample room for different interpretations, and implant suspicion in non-experts.

Good communication is certainly a necessary condition for improving trustworthiness, but engagement of citizens in the process of building, spreading and responsible use of science is thought to have a high potential for success (European Commission 2013).

Public engagement with science strengthens citizenship skills and empowerment; it increases awareness of the cultural relevance of science, and recognition of the importance of multiple perspectives and domains of knowledge to scientific endeavors (Annual Report AAAS 2015).

In this frame a participatory approach to Natural Hazard education has a high value. Here we describe two cases study that focuses on student engagement in hydrogeologic risk reduction. We start from local memory of catastrophic events that occur in the Italian region involved in our program, which is tested in Liguria. La Spezia and Genova Provinces has been repeatedly affected by severely damaging floods throughout its history. The intervals between floods are too often very short and people are afraid when heavy rain strikes.

\section{Land, Hazard and Risk}

Mountains and hills correspond to the $77 \%$ of Italian land, most of which has steep slopes or clay-based composition (Fig. 1). Recent mapping has shown for the northern part of the country and in Emilia, Liguria and Tuscany regions a high level of hazard for flood and landslides. After World War II Italy underwent heavy urbanization without taking into account the areas with high level of hydrogeologic hazards. Moreover population moved from mountains to cities and abandoned land.

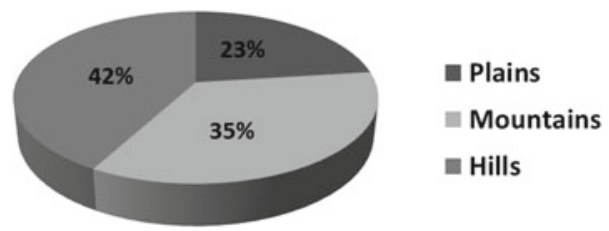

Fig. 1 Land distribution in Italy
Terraces, traditionally sustained by dry stonewalls, occupy about thirty percent of the territory of Liguria. If constantly maintained, they effectively contribute to slow down the natural slope erosion. When no longer managed, terraces may increase geomorphological risk along the slopes and, consequently, at the bottom of the valley (Brandolini et al. 2012).

Bad weather such as flash rain worsen the background hazard causing severe damages and devastation across Italy and weight over the economy of a country that has to faces a large variety of disasters. Italy faces emergency but efforts on prevention are not enough to deal with the problem. Emergency often announced with "state of alert", and results in schools closure to try minimize the number of people on the roads during heavy rain. In addition to damage to infrastructure and housing, bad weather also affects agriculture. According to Coldiretti (Italy's largest agricultural association) heavy rain, overflown rivers and landslides will cost millions of euros to the agricultural sector due to land and crop damage. Farmland overflown with water, vegetables production and plants cultivation located near rivers registered the worst images.

The terraced landscape is very common in the Ligurian region, covering about of the $30 \%$ of the territory. Agricultural terraces are sustained by dry stonewalls and reduce the slow down the natural slope erosion, but if no regularly maintained, can worst the risk of landslides and "detritus flow".

Since 1970 recurring floods affect Genoa where the Bisagno Stream catchment flows across the eastern part of city center. The most recent and tragic was in October 2014 (Faccini et al. 2016).

The 5 Terre peculiarity of little towns cling to sheer hills along a narrow, rugged strip of land between the Maritime Alps, the Apennine Mountains and the Ligurian Sea is results into a heavy geo-hydrological risk. The fragile land conditions turn into instability during unusual meteorological conditions that causes heavy flooding. This happened in October 2011 when the river rushed violently down dislocating and destroying several towns, redefining the natural architecture of the affected the Vara and Magra Valleys near La Spezia (Piangiamore et al. 2015) (Figs. 2 and 3).

\section{Materials and Methods}

Floods and landslides may strongly affect lives of many people. Emotional-learning activities can activate a life long learning process developing skills that might end up being fundamental for the own safety (Piangiamore et al. 2012).

To engage students into an active learning path and a flipped-up learning strategy we have to listen them and exchange ideas and experiences. 


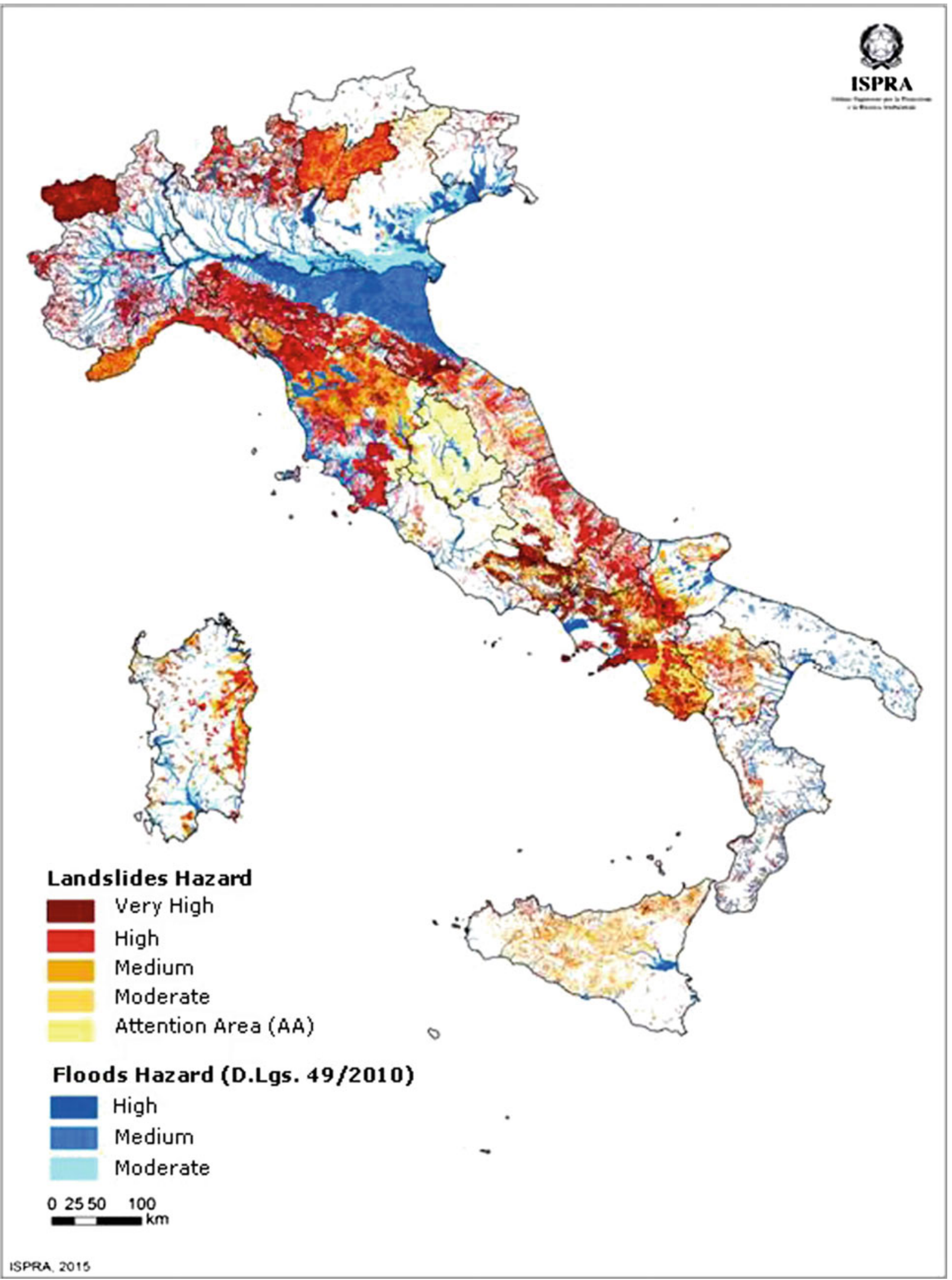

Fig. 2 Landslides and floods hazard map (Trigila et al. 2015) 


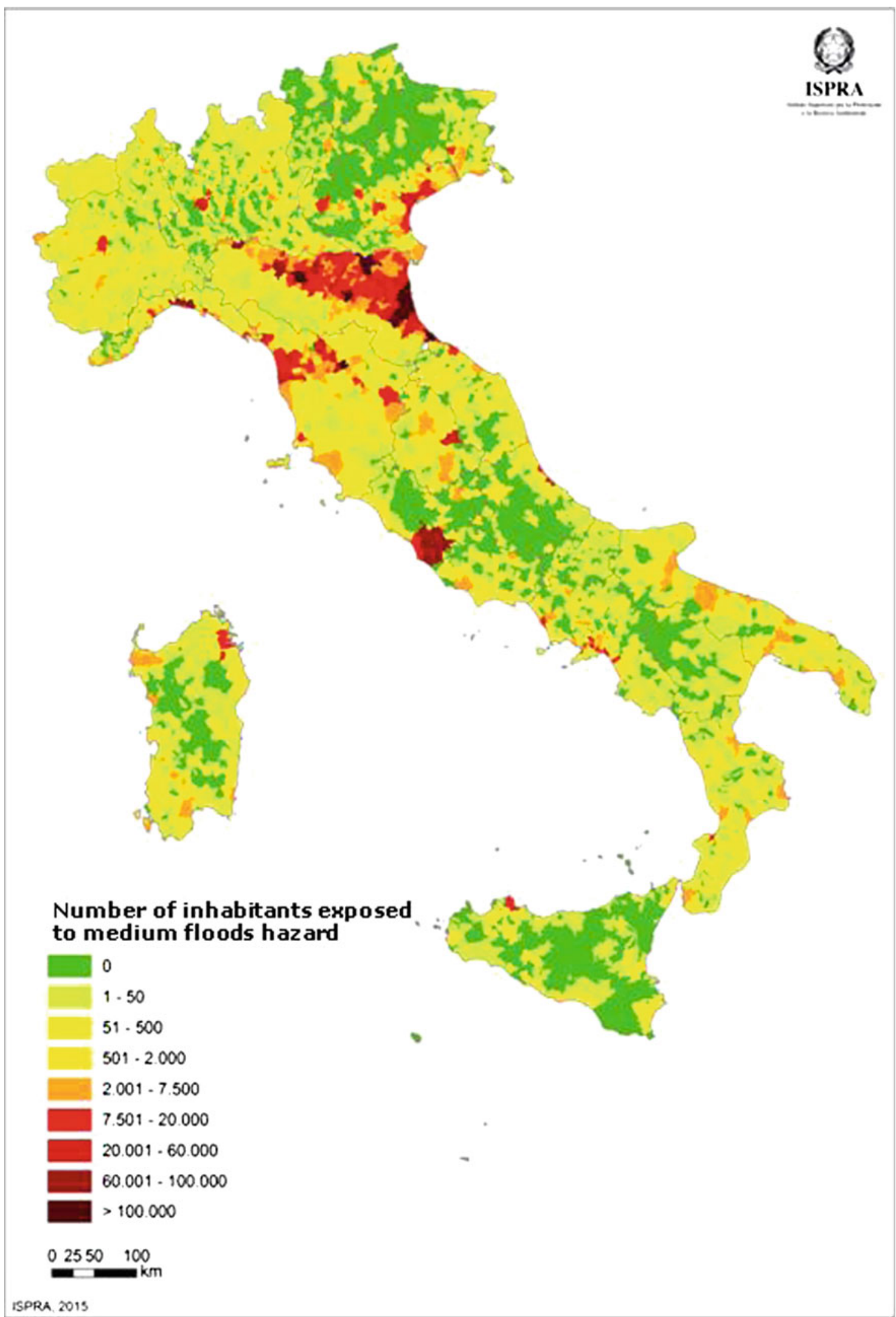

Fig. 3 Inhabitants exposed to medium floods hazard (D.Lgs. 49/2010) 
More than lack of knowledge is a question of understanding their needs and interests.

In approaching risk communication and learning, we test different ways and methods from 2004 to nowadays. Here we describe two cases study we develop in the last four years in which students and experts have collaborated in preparing (1) a participated exhibition on the 2011 flood that severely hit the land of La Spezia and surrounding, and (2) a flipped-up learning tool.

The participated exhibition is Piovono Idee! (Cloudy with a Chance of ideas!) and it is the result of experts' interaction directly in school, focus groups and hands on activities. Students involved had experience the disaster and could put their emotion into their products. Exhibits of the interactive path tell us their own history.

Primary and secondary schools in areas strongly affected by the flood of the 25th October 2011-Borghetto Vara, Brugnato, Monterosso, Vernazza, Riomaggiore, Pignone, Riccò del Golfo, Aulla and Ragnaia (Aulla) - and secondary schools from the city of La Spezia were directly involved in the participatory action. Planning, creation and exhibition were the three main phases of the action to improve their specific scientific knowledge with hands-on activities, while exploring feelings and emotions triggered by the experience of a flood. The learn-by playing approach is also used to instil appropriate behaviours and the awareness that every actions we take derives from a choice: we can chose whether or not be respectful towards nature. Even little actions can turn into negative or positive consequences as it is sudden evident in Piovono idee!. Indeed the learning path starts with the question: 'Is nature scary?' shows a colored and smiling Nature full of gifts, which can became angry simply poking on it. The discovery of hydrogeological risk continues focusing on the importance to respect territory and on the correct land use with different totems, exhibits, experiments, scientific games. It emotionally involves the participants to favor reflective learning (Piangiamore et al. 2014, 2015). The latest activities are two role games to enforce eco-friendly behaviors for hydrological risk mitigation.

A few years later, Piovono idee! was updated and the exhibition got fully portable since 2015 and ready to travel the schools of the country to involve as many citizens as possible. The second edition of Piovono idee! (Fig. 4) is also an example of peer-education activity as students of the High School of La Spezia and of the Secondary school of Lerici, that were not directly and emotionally involved in the disaster, have played the role of the guides for general public (Bernhardsdóttir et al. 2012; Piangiamore et al. 2016).

The flipped-up learning tool is the EAS Floods: what to do?, an application of the Episodes of Situated Learning (EAS) method to natural hazard education (Rivoltella 2014; Piangiamore et al. 2015). The EAS method acts on problem solving abilities that the classroom shared among peer and with the mentor and ends with a reflective learning approach where concepts are reworked and restructured. We applied this interactive approach to natural hazards at school to stimulate best practice for the good of all. Researchers and teachers worked side by side designed Floods: what to do? on hydrogeological hazard active learning to promote knowledge and safety.

This is a way for education of the new generations intriguing students to arouse their interest towards environmental problems, generally underestimated by formal education (Muttarak and Lutz 2014). Floods: what to do? asks students to prepare a tool capable of effective communication to their peers and to the public, involving them in three phase: (1) the preparation phase based on problem-solving; (2) the activity phase based on learning by doing; and (3) the debriefing phase based on reflective learning.

In (1) the teacher gives inputs to make them curious on hydrogeological matter using Internet and web browsing. Students watch short-shoots of videos, presentations or a text inputs surfing on selected websites at home prior lesson.

In (2) the teacher's conceptual framework on hydrogeological, geomorphological, water drainage risks and climate change. Then students do a cooperative work gathered in small groups by means of specific application to build comics (e.g., Comic Life, Comic Maker, Bistrips, Pixton Comics) freely available on the Internet. The results are comics to communicate the safe behaviors and the basics of self-protection in case of natural extraordinary events.

In (3) the teacher makes assessments, discusses misconception and define concepts. Students analyze their classmates' products, discusses with them and reflects on crucial aspects of behaviors that can save lives discovering together the territory they live in.

Students are familiar with comics, their products are set in a familiar environment such as at home, at school, in a narrow road, in an open space, next to a river bank, in a woods, in the fields, etc. This is an amusing way to raise awareness on disaster reduction and risk education enforcing the ability to foster hazards before the occur of extreme events.

\section{Results}

The two case studies were useful to document educational tools and engagement initiatives to ensure effective dissemination and communication and raise public awareness and understanding in countries exposed to hydro and geomorphological hazard. Global promotion of understanding and reducing hydrogeological disaster risk is one of the ambitious mandate for the next 15 years at the 3rd United Nations World Conference in Japan. The principle of 'risk-informed decision-making' involve application of risk 


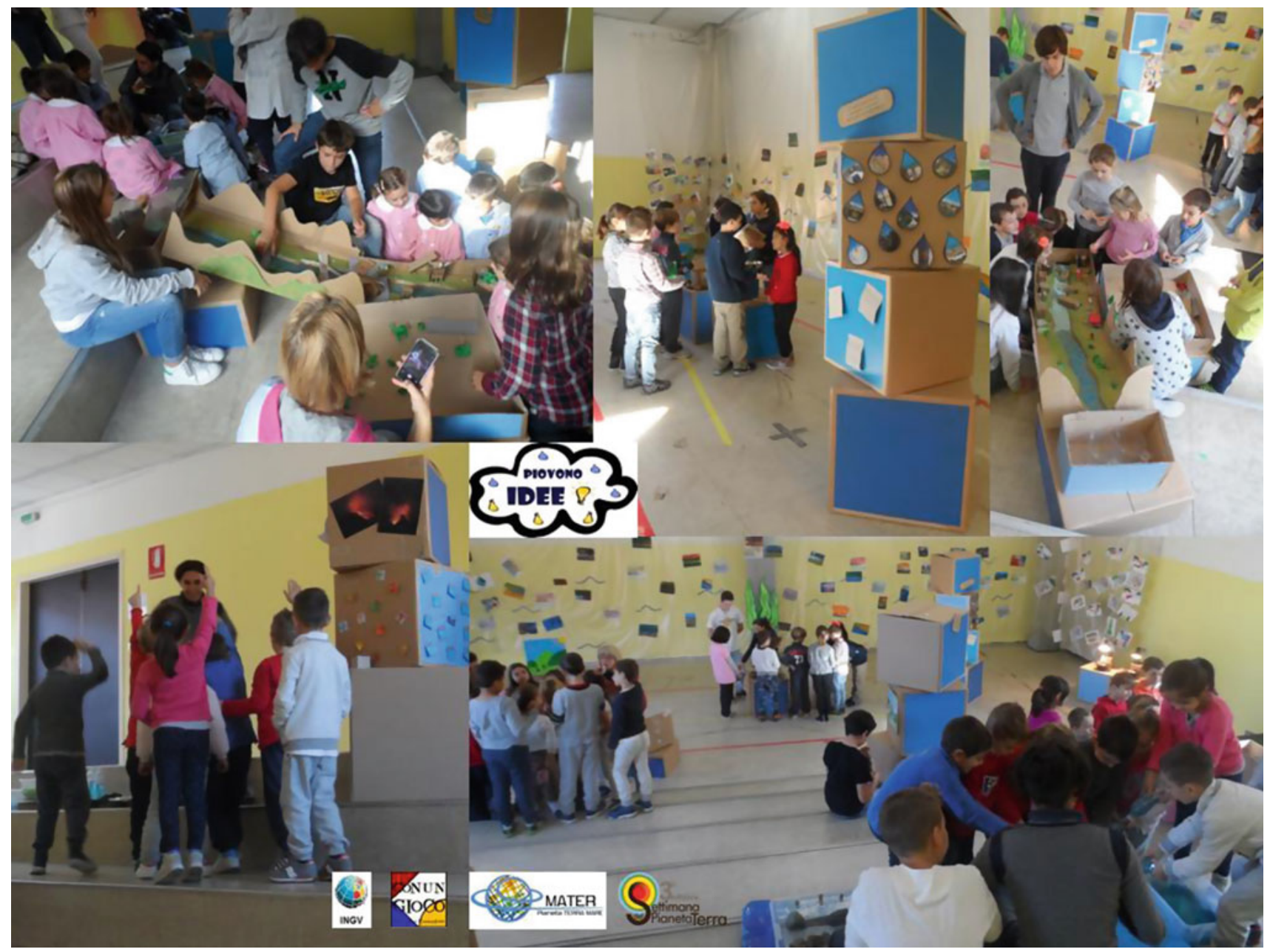

Fig. 4 The second edition of Piovono idee! with peer-education activity. Students of the high school and of the secondary school are the guides of the learning path. Hands-on activities are completely

information at all levels (UNISDR 2005, 2015). We promote responsibility for enhancing international science and technology cooperation by engaging students and teachers on disaster risk reduction attitude for a resilient community.

Resilience is the capacity to withstand and recover quickly from extreme dissemination strategies to instill a culture of safety will exploit some new aspects for the promotion of best practice.

Italy bad weather emergency reveals the country's lack of readiness for hydrogeological risk prevention plans. Flood and landslide risk education can contribute to advancing culture of living with natural hazards and to reduce landslide and flood disaster risk. The necessity to dialogue about this theme has to be a priority for the risk governance and management to establish an effective hydrogeological reduction. The experiences here designated has reached students and adults with excellent feedbacks, supported by questionnaires and press releases. These example of good interactive and made of simple materials (mainly cardboard) to improve scientific knowledge while exploring emotions triggered by the experience of a flood

cooperation incorporating many relevant stakeholders into a risk dialogue, enforcing the common aim to build a sustainable system of prevention for prepared future citizens able to respect natural environment and Nature.

Acknowledgements About Piovono idee! we are grateful to D. Modenesi and F. Brasini (ConUnGioco Onlus), R. Camassi (INGV Bologna), M. Miconi (INGV Roma), M. Bocchia, G. Mancini, C. Cassinoni, S. Lualdi, M. Lombardo and G. Savoldi, M. Biso (La Spezia Provincial Civil Protection Service); M. Casarino, P. Milano and O. Zocco (La Spezia Provincial Europe Service, Coordination of Municipalities), G. Forlani, M. S. Ariodante, A. M. Bimbi (La Spezia Prefect's Office's Civil Protection Department), MARIDIPART, MARICOMMI, the voluntary Civil Protection associations and the GEV of the Province of La Spezia and many thanks to all the Province of La Spezia primary and lower secondary schools contributing to our initiative (Borghetto Vara, Brugnato, Monterosso, Vernazza, Riomaggiore, Pignone, Riccò del Golfo, Aulla e Ragnaia (Aulla) and "V. Alfieri", "U. Mazzini" and "J. Piaget" of La Spezia. About Piovono idee! second edition we acknowledge D. Modenesi and F. Brasini (ConUnGioco Onlus), R. Camassi (INGV Bologna), S. Merlino 
(CNR-ISMAR of La Spezia), the secondary schools of "ISA 10" (Lerici) and the High School "Pacinotti" (La Spezia). About EAS (Episodes of Situated Learning) for natural risk reduction at school we would like to thank Monica De Vecchi (Comprehensive Institute "Voltri 1" of Genova) and Alessandra Carenzio (Professor at the University "Cattolica del Sacro Cuore" of Milan). Piovono idee! was funded by Province of Spezia within the framework of the 'Laboratories of shared and participatory citizenship- IV edition' project promoted by the Directorate-General for the Third Sector and Social Formations- Italian Ministry of Labour. Piovono idee! second edition was funded by MIUR (Italian Ministry of Education, University and Research) inside the Dissemination of Scientific and Technological Culture call for the year 2014 within the framework on 'MATER Pianeta Terra-Mare (Planet Earth and Sea)'.

\section{References}

Bernhardsdóttir AE, Thorvaldsdóttir S, Sigbjörnsso R, Musacchio G, Nave R, Falsaperla S, D'Adda S, Sansivero F, Zonno G, Sousa ML, Carvalho A, Raposo S, Ferreira MA, Nunes JC, Jimenez MJ (2012) Disaster prevention strategies based on an education information system. In: Proceedings of the 15th WCEE, 2012. Lisbona, Portugal. http://hdl.handle.net/2122/8148

Brandolini P, Cevasco A, Firpo M, Robbiano A, Sacchini A (2012) Geo-hydrological risk management for civil protection purposes in the urban area of Genoa (Liguria, NW Italy). Nat Hazards Earth Syst Sci 12:943-959. www.nathazards-earth-syst-sci.net/12/943/ 2012/. doi:10.5194/nhess-12-943-2012

Commission European (2013) Science for an informed, sustainable and inclusive knowledge society, Policy paper by President Barroso's Science and Technology Advisory Council, 29 August 2013. Brussels, Belgium

Faccini F, Giostrella P, Paliaga G, Piana P, Sacchini A (2016) The role of historical agricultural terraces in geo-hydrological risk reduction: a case study from the Bisagno Stream Catchment (Genoa, Italy). Geophysical Research Abstracts, vol 18. EGU2016. Vienna, Austria, p 7441

Muttarak R, Lutz W (2014) Is education a key to reducing vulnerability to natural disasters and hence unavoidable climate change? Ecol Soc 19(1):42. doi:10.5751/ES-06476-190142

Piangiamore GL, Fanelli E, Furia S, Garau D, Merlino S, Musacchio G, Centineo MC (2016) MATER - Pianeta Terra-Mare: an interactive and multidisciplinary approach to Geosphere sciences. Geophysical
Research Abstracts, vol 18. EGU 2016. Vienna, Austria, pp 1029810303

Piangiamore GL, Musacchio G, Devecchi M (2015) Situated learning episodes: natural hazards active learning in a smart school. In: Interactive learning: strategies, technologies and effectiveness. NOVA, New York, USA. https://www.novapublishers.com/ catalog/productinfo.php?products_id $=56608$

Piangiamore GL, Musacchio G, Pino NA (2015) Natural hazards revealed to children: the other side of prevention. In: Peppoloni S, Di Capua G (eds) Geoethics. The Role and Responsibility of Geoscientists, Geological Society Special Publications, London, p 419. http://dx.doi.org/ 10.1144/SP419.12

Piangiamore GL, Musacchio G, Bocchia M (2014) Piovono idee! (cloudy with a chance of ideas!): an interactive learning experience on hydrogeological risk and climate change. In: Lollino G, Arattano M, Giardino M, Oliveira R, Peppoloni S (eds) Engineering geology for society and territory, vol 7. Education, Professional Ethics and Public Recognition of Engineering Geology, Turin, Italy, pp 121-124

Piangiamore GL, Musacchio G, Bocchia M (2013). Challenging risk reduction through education and preparedness. In: Proceedings of the 32th GNGTS, 2013, Trieste, Italy, vol 2, pp 446-452

Piangiamore GL, Pezzani A, Bocchia M (2012) ERiNat project (training on natural risks): from informed children to knowledgeable adults. In: Proceedings of the 7th EUREGEO-European congress on regional geoscientific cartography and information systems, 2012, vol 1, Bologna, Italy, pp 321-322

Rivoltella PC (2014) Episodes of situated learning. A new way to teaching and learning. In: Research on education and media, VI, N. 2, pp 79-87. http://ojs.pensamultimedia.it/index.php/rem_en/article/ view/1070

The American Association for the Advancement of Science (AAAS) (2015) Annual report. Innovation, information and imaging. http:// annualreport.aaas.org/?utm_source=aaasorg\&utm_medium= aboutpg\&utm_campaign=2015AnnualReport

Trigila A, Iadanza C, Bussettini M, Lastoria B, Barbano A (2015) Dissesto idrogeologico in Italia: pericolosità e indicatori di rischio. Annual report. ISPRA, 233/2015

UNISDR (2005) Hyogo framework for action 2005-2015: building the resilience of nations and communities to disasters, international strategy for disaster reduction. http://www.unisdr.org/2005/wcdr/intergover/ official-doc/L-docs/Hyogo-framework-foractionenglish.pdf

UNISDR (2015) Sendai framework for disaster risk reduction 20152030. http://www.preventionweb.net/files/43291_sendaiframework fordrren.pdf
Open Access This chapter is licensed under the terms of the Creative Commons Attribution 4.0 International License (http:// creativecommons.org/licenses/by/4.0/), which permits use, sharing, adaptation, distribution and reproduction in any medium or format, as long as you give appropriate credit to the original author(s) and the source, provide a link to the Creative Commons license and indicate if changes were made.
The images or other third party material in this chapter are included in the chapter's Creative Commons license, unless indicated otherwise in a credit line to the material. If material is not included in the chapter's Creative Commons license and your intended use is not permitted by statutory regulation or exceeds the permitted use, you will need to obtain permission directly from the copyright holder. 